\title{
Current status and future prospects of PET/CT in NSCLC treated with checkpoint-based immunotherapy
}

\author{
Mitsunori Higuchi*, Tetsutaro Nemoto², Hajime Matsuida², lkuro Oshibe², Nobutoshi Soeta², Toshiyuki Takeshige², \\ Takuro Saito ${ }^{2}$, and Hiroyuki Suzuki ${ }^{3}$ \\ 'Department of Thoracic Surgery, Aizu Medical Center, Fukushima Medical University, Fukushima, 969-3492, Japan \\ ${ }^{2}$ Department of Surgery, Aizu Medical Center, Fukushima Medical University, Fukushima, 969-3492, Japan \\ ${ }^{3}$ Department of Chest Surgery, Fukushima Medical University School of Medicine, Fukushima, 960-1295, Japan
}

Article Info

\section{Article Notes}

Received: February 21, 2017

Accepted: March 13, 2017

\section{*Correspondence:}

Mitsunori Higuchi, MD, PhD

Department of Thoracic Surgery, Aizu Medical Center,

Fukushima Medical University, 21-2 Maeda Tanisawa

Kawahigashi Aizuwakamatsu Fukushima, 969-3492, Japan,

Tel: +81-242-75-2100; Fax: +81-242-75-2568; E-mail:

higuchi@fmu.ac.jp

(c) 2017 Mitsunori Higuchi. This article is distributed under the terms of the Creative Commons Attribution 4.0 International License.

\section{Keywords}

18F-Fluorodeoxyglucose Positron-emission Tomography (FDGPET)

Computed Tomography (CT)

Immune Checkpoint Inhibitor

Immunometabolism

Chemotherapy

Non-Small Cell Lung Cancer (NSCLC)

\section{ABSTRACT}

Immune checkpoint inhibitors play crucial roles in the treatment of advanced and recurrent non-small cell lung caner (NSCLC). As yet, there are no biomarkers to help select patients that would benefit from this treatment. Currently, evaluation of the efficacy of immune checkpoint inhibitors is performed using Response Evaluation Criteria In Solid Tumors (RECIST) or immune-related response criteria on the basis of computed tomography (CT) scans, which are based only on anatomical changes and exclude a metabolic assessment. 18F-fluorodeoxyglucose positron emission tomography (FDG-PET) can add metabolic information, but is also subject to false-positive and falsenegative findings in the presence of inflammation. In this review, we briefly discuss the optimal use of FDG-PET for the evaluation of checkpoint-based cancer immunotherapy and also discuss the relationship between immune checkpoint inhibitors and FDG-PET in NSCLC. We also introduce ongoing clinical studies and pre-clinical experiments involved in the development of diagnostic imaging and treatments for NSCLC.

\section{Introduction}

Lung cancer is the leading cause of cancer-related death worldwide $^{1}$. Third-generation platinum doublets, epidermal growth factor receptor (EGFR) tyrosine kinase inhibitors (TKIs) in sensitized EGFR mutation-positive lung cancer, anaplastic lymphoma kinase (ALK) TKIs in ALK rearrangement-positive disease, anti-vascular endothelial growth factor (VEGF) antibody, anti-VEGF receptor (VEGFR) antibody, maintenance systemic therapy, and second- or third-line treatment have improved survival in patients with non-small cell lung cancer (NSCLC) ${ }^{2-9}$. To date, immune checkpoint inhibitors have been introduced ${ }^{10-12}$. Nivolumab, one of immune checkpoint inhibitors that is an antibody against programmed death-1 (PD-1), causes $\mathrm{T}$ cell activation and demonstrates antitumor activity through the blockade of combination between PD-1 and its ligand, programmed death ligand-1 (PD-L1). In some phase III trials, overall survival (OS), objective response rate (ORR), and progression free survival (PFS) were better with nivolumab than with chemotherapy in NSCLC (Checkmate 017 and Checkmate 05713,14). Furthermore, pembrolizumab, also an immune checkpoint inhibitor that is also an antibody against PD-1, has been reported in the KEYNOTE 024 phase III trial ${ }^{15}$ to have superior PFS, OS, and ORR compared 


\begin{tabular}{|c|c|c|c|c|c|c|c|}
\hline Immunotherapy & Year & $\begin{array}{l}\text { Target } \\
\text { molecule }\end{array}$ & Phase & $\mathrm{N}$ & Primary endpoint & Results & $\begin{array}{l}\text { Reference } \\
\text { No. }\end{array}$ \\
\hline Nivolumab & 2015 & PD-1 & III & 272 & Overall survival & $\begin{array}{l}\text { At } 1 \text { year, the overall survival rate was } 42 \% \text { ( } 95 \% \mathrm{Cl}, 34 \text { to } 50) \\
\text { with nivolumab versus } 24 \%(95 \% \mathrm{Cl}, 17 \text { to } 31) \text { with docetaxel. }\end{array}$ & 13 \\
\hline Nivolumab & 2015 & PD-1 & III & 582 & Overall survival & $\begin{array}{l}\text { At } 1 \text { year, the overall survival rate was } 51 \%(95 \% \mathrm{Cl}, 45 \text { to } 56) \\
\text { with nivolumab versus } 39 \%(95 \% \mathrm{Cl}, 33 \text { to } 45) \text { with docetaxel. }\end{array}$ & 14 \\
\hline Pembrolizumab & 2016 & PD-1 & III & 305 & $\begin{array}{l}\text { Progression-free } \\
\text { survuval }\end{array}$ & $\begin{array}{l}\text { Median progression-free survival was } 10.3 \text { months } \\
(95 \% \text { confidence interval }[\mathrm{Cl}], 6.7 \text { to not reached) in the } \\
\text { pembrolizumab group versus } 6.0 \text { months }(95 \% \mathrm{Cl}, 4.2 \text { to } \\
6.2 \text { ) in the chemotherapy group (hazard ratio for disease } \\
\text { progression or death, } 0.50 ; 95 \% \mathrm{Cl}, 0.37 \text { to } 0.68 ; \mathrm{P}<0.001 \text { ). }\end{array}$ & 15 \\
\hline Ipilimumab & 2012 & CTLA-4 & II & 204 & $\begin{array}{l}\text { Immune-related } \\
\text { progression-free } \\
\text { survuval }\end{array}$ & $\begin{array}{l}\text { Phased ipilimumab improved irPFS compared with the } \\
\text { control (hazard ratio [HR], 0.72; } P=.05 \text { ). }\end{array}$ & 24 \\
\hline Atezolizumab & 2017 & PD-L1 & III & 850 & $\begin{array}{l}\text { Overall survival } \\
\text { and PD-L1 } \\
\text { expression } \\
\text { population }\end{array}$ & $\begin{array}{l}\text { Overall survival in the TC1/2/3 or IC1/2/3 population was } \\
\text { improved with atezolizumab ( } \mathrm{n}=241 \text { ) compared with } \\
\text { docetaxel }(\mathrm{n}=222 ; \text { median overall survival was } 15 \cdot 7 \text { months } \\
{[95 \% \mathrm{Cl} 12 \cdot 6-18 \cdot 0] \text { with atezolizumab vs } 10 \cdot 3 \text { months }} \\
{[8 \cdot 8-12 \cdot 0] \text { with docetaxel; HR } 0 \cdot 74[95 \% \mathrm{Cl} 0 \cdot 58-0 \cdot 93]} \\
\mathrm{p}=0.0102) \text {. }\end{array}$ & 68 \\
\hline $\begin{array}{l}\text { Durvalumab } \\
\text { with or without } \\
\text { tremelimumab }\end{array}$ & 2016 & PD-L1 & Ib & 102 & Safety & $\begin{array}{l}\text { Treatment-related serious adverse events occurred in } 37 \\
\text { (36\%) of } 102 \text { patients, and three deaths were related to } \\
\text { treatment }\end{array}$ & 70 \\
\hline
\end{tabular}

Table 1: Clinical studies of checkpoint-based immunotherapy for NSCLC

to platinum-based cytotoxic chemotherapy as a firstline treatment for NSCLCs with $\geq 50 \%$ positive PD-L1 expression. We showed previous clinical studies of checkpoint-based immunotherapy for NSCLC in Table 1.

Contrast-enhanced computed tomography (CT) and magnetic resonance imaging (MRI) have been used to stage and follow up various malignancies before and after treatment ${ }^{16-18}$. 18F-fluorodeoxyglucose-positron emission tomography (FDG-PET) is an effective tool for metabolically assessing treatment response and surveillance of disease status. However, it sometimes shows increased FDG uptake at sites of local inflammatory changes caused by the accumulation of inflammatory cells ${ }^{19}$. Many researchers have reported the utility of FDG-PET or FDG-PET/CT in evaluating therapeutic response to date ${ }^{20-23}$. In this review, the role of PET/CT after treatment with immune checkpoint inhibitors is highlighted and the following topics are discussed: (a) Use of immune checkpoint inhibitors in NSCLC; (b) Tumor microenvironment and metabolic variables; (c) Imaging comparison between FDG-PET and CT scan; (d) Development of molecular imaging criteria for staging and surveillance; (e) Pitfalls and clinical questions; (f) Clinical trials using PET imaging for evaluating immune checkpoint inhibitors; and (g) Conclusions and future directions.

\section{Use of immune checkpoint inhibitors in NSCLC;}

In patients with recurrence after surgery for NSCLC or advanced NSCLC, who have relapsed after previous platinum-based chemotherapy, docetaxel monotherapy is considered to be the current standard treatment regimen ${ }^{5,7}$. Recent prospective studies including CheckMate $017^{13}$ and CheckMate $057^{14}$ showed that nivolumab was superior to docetaxel for squamous cell carcinoma ${ }^{13}$ and non-squamous cell carcinoma ${ }^{14}$ previously treated with platinum-based agents. Based on these randomized controlled trials, one of the current second line chemotherapies in patients failing platinum-based chemotherapy is considered to be nivolumab. Pembrolizumab is a humanized monoclonal antibody against PD-1. A recent prospective study showed that in patients with advanced NSCLC and PD-L1 expression by at least $50 \%$ of tumor cells, pembrolizumab was associated with significantly longer PFS and OS (KEYNOTE $024^{15}$ ). Based on these results, in patients with advanced NSCLC and recurrent NSCLC after surgery with PD-L1 expression $\geq 50 \%$, pembrolizumab is recommended as first-line immunotherapy. Ipilimumab is a fully humanized IgG1 anti-cytotoxic T lymphocyte antigen-4 (CTLA-4) monoclonal antibody that blocks the binding of CTLA-4 to its ligand, B7.1. A randomized phase II clinical study assessed treatment effects with paclitaxel and carboplatin with or without ipilimumab in treatment-naïve stage IV NSCLC patients $^{24}$. In that study the patients showed improvement in immune-related PFS when ipilimumab was administered after chemotherapy (5.7 versus 4.6 months, respectively, $\mathrm{P}=0.05$ ). A phase III clinical trial to investigate whether ipilimumab plus paclitaxel and carboplatin will extend the OS of patients with squamous NSCLC compared to placebo plus paclitaxel and carboplatin is ongoing (NCT01285609). 


\section{Tumor microenvironment and metabolic} variables;

In addition to neoplastic cells, the tumor microenvironment consists of various cell types such as tumor infiltrating lymphocytes (TILs) and tumorassociated macrophages (TAMs) ${ }^{25,26}$. It has been shown that tumor infiltrating leukocytes may display opposite functions and a wide extent of heterogeneity, depending on the primary tumor location and stage of disease $\mathrm{e}^{27,28}$. The potential ability of immune cells for tumor control is reflected in the behavior of TILs in some solid tumors ${ }^{29,30}$. And immune-related variables could be helpful biomarkers of prognosis and surrogate endpoints of treatment responses ${ }^{31,32}$. FDG is actively incorporated in neoplastic tissue and tumor-related activated immune cells such as TILs and TAMs as a glucose analogue ${ }^{33,34}$. Therefore, FDGPET could provide valuable information on the metabolic status of the tumor microenvironment. Chang et $a l^{35}$ suggested that glucose consumption had restricted $\mathrm{T}$ cells metabolically, weakening their effector functions. Lopci, et $a l^{36}$ reported an association between metabolic parameters on FDG-PET and the expression of tumor-related immunity markers. That study suggested a potential role for FDG-PET to characterize the tumor microenvironment and select NSCLC candidates to checkpoint inhibitors ${ }^{36}$.

\section{Imaging comparison between FDG-PET and CT scan;}

FDG-PET can evaluate viable cells and it is considered to be more sensitive than CT for detection of solitary primary lung tumors ${ }^{37,38}$. Some previous prospective studies showed that FDG-PET/CT had $96 \%$ sensitivity and $82-88 \%$ specificity when compared with sensitivity and specificity of $96 \%$ and $53 \%$ of $\mathrm{CT}^{37,39}$. In identification of pulmonary tumor, metabolic assessment with FDG-PET is considered to be superior to clinical and morphological criteria ${ }^{40}$. FDGPET is accurate in differentiating benign from malignant lesions as small as $1 \mathrm{~cm}^{41}$, and overall sensitivity of $96 \%$ (range, $83-100 \%$ ), specificity of $79 \%$ (range, $52-100 \%$ ), and accuracy of $91 \%$ (range, $86-100 \%$ ) can be expected by previous studies ${ }^{42-44}$. We previously showed the usefulness of maximum standardized uptake value (SUVmax) for the prognosis of patients with pathological stage I lung adenocarcinoma. In that report, we calculated SUVmax cut-off value as 2.5 according to receiver operating characteristic (ROC) curve, and also showed that diseasefree survival (DFS) after surgery less than 2.5 of SUVmax was significantly better compared with the patients more than 2.5 of SUVmax ${ }^{45}$. However, these results are dependent on SUVmax cut-off values, which differed in each institution, and there is no universal value. To resolve this problem, Shiono, et $a l^{46}$ demonstrated a corrected SUV, which they termed the SUV index, and calculated this as the ratio of tumor SUVmax to liver mean SUV (SUVmean). They reported this SUV index was reproducible and was a significant predictor of NSCLC recurrence. Many investigators have also reported the utility of FDG-PET in evaluating therapeutic response ${ }^{20-22}$. Complete disappearance of FDG accumulation is an indicator of a low probability of local recurrence and better prognosis after local treatments such as surgery and radiation therapy, and systemic chemotherapy in patients with lung cancer ${ }^{47-51}$.

The optimal follow-up schedule by FDG-PET scan during immunotherapy is controvertial. Some prospective studies (Checkmate $017^{13}$ and Checkmate 057 ${ }^{14}$ ) have suggested an evaluation schedule of immune checkpoint inhibitors of every eight weeks. In the KEYNOTE024 trial $^{15}$, imaging studies of the tumor were scheduled every nine weeks. However, these intervals are somewhat short for FDG-PET. In practice, the physician might evaluate the effects of immune checkpoint inhibitors by CT scan every eight or nine weeks and by FDG-PET every 16 to 18 weeks.

Zhang L, et al. ${ }^{52}$ evaluated the diagnostic performance of dual time point FDG-PET/CT in the diagnosis of pulmonary nodules. Dual time point imaging technique conducts additional measurements at a second time point after the single time point, with 1.5 to 4 hours. They showed that dual time point and single time point studies had similar accuracy in the differential diagnosis of pulmonary nodules. They did conclude, however, that dual time point examinations appear to be more specific than single time point examinations. Therefore they recommended dual time point imaging for more accurate diagnosis. There are also some interesting reports ${ }^{53,54}$, which demonstrated that pretreatment values of metabolic tumor volume (MTV) and total lesion glycolysis (TLG) were the prognostic factors in patients with some solid cancer. These parameters are quantitative volume parameters calculated from glucose uptake. MTV was defined as total tumor volume with FDG uptake segmented by fixed threshold methods at various rates of SUVmax. TLG values were calculated by multiplying the MTV and SUVmean values. These parameters also have potential to provide prognostic information in NSCLC patients treated with immune checkpoint inhibitors as well as chemotherapy and radiotherapy.

\section{Development of molecular imaging criteria for staging and surveillance}

Although we usually evaluate the tumor response with RECIST $^{55}$ or immune-related Response Criteria (irRC) ${ }^{56}$ after cancer treatment, there are two sets of response criteria using PET. The European Organization for Research and Treatment of Cancer (EORTC) criteria are the first metabolic criteria for solid tumors, which were published in $1999^{57}$. EORTC criteria are based on the most FDG-avid lesions at baseline that are followed on each subsequent scan. Wall, et al..$^{58}$ proposed PET Response Criteria in Solid Tumors (PERCIST), which operates with a fixed ROI of 1 
$\mathrm{cm}^{3}$ to assess the most FDG-avid part of the single most metabolically active tumor in the patient at each PET/ CT scan. In these criteria, tumor responses are divided into four categories: complete metabolic response (CMR), partial metabolic response (PMR), stable metabolic disease (SMD), and progressive metabolic disease (PMD). Although some previous reports demonstrated that there was concordance between EORTC criteria and PERCIST in the assessment of the tumor response in patients with solid tumors ${ }^{59,60}$, prospective studies using EORTC criteria and PERCIST are lacking. However, the metabolic evaluation criteria by both EORTC and PERCIST would be also helpful to evaluate the metabolic treatment effects in the cases of FDG-PET as well as anatomical evaluation by RECIST in the future, even in the patients with immunotherapy.

\section{Pitfalls and clinical questions;}

Immune checkpoint inhibitors has a potential problem, because the inflammatory changes caused by the accumulation of neutrophils, lymphocytes and macrophages ${ }^{15}$ may lower the specificity because these cells take up FDG. Furthermore, immune checkpoint inhibitors activate $\mathrm{T}$ cells, which infiltrate tumor tissue. However, these TILs have been considered to be a potential biomarker for both selection of candidates and monitor of checkpoint-based immunotherapy. In this way, T cells have both positive effects of anti-cancer activity and adverse effects for the evaluation of immunotherapy with PET. We need to recognize these phenomena affected by T cells.

In fact, there are only few reports, which showed the usefulness of FDG-PET/CT to evaluate the efficacy of immune checkpoint inhibitor ${ }^{61,62}$. Kong BY, et al. ${ }^{63}$ also reported that patients with residual metastases, which were no FDG uptake but detected anatomically by CT scan , after a prolonged period without progression on anti-PD-1 therapy might have metabolically inactive lesions.

If the TILs are an important factor and biomarker for predicting the efficacy of immune checkpoint inhibitors, the question follows as to whether the efficacy of immune checkpoint inhibitors might be higher in metastatic lymph nodes because of their rich populations of lymphocytes. We have previously shown more effective reduction of FDG accumulation in involved lymph nodes compared with other metastatic sites ${ }^{62}$. We need more detailed studies to elucidate this question.

PD-L1 expression is thought to be a dynamic marker during some treatments, as the expression of PD-L1 has been changed over time according to the microenvironmental changes. Because of these phenomena, the lack of imaging tools to accurately assess this dynamic immune checkpoint expression can create a barrier to validating some biomarkers for the prediction and monitoring of responders to clinical checkpoint inhibit.

An urgent issue to be resolved is to explore more specific biomarkers of this treatment and to develop better imaging systems for accurate surveillance, as checkpoint-based immunotherapy shows promise to improve the prognosis of patients with advanced or recurrent NSCLC.

\section{Clinical trials using PET imaging for evaluating immune checkpoint inhibitors;}

Some clinical studies (UMIN000020707 and UMIN000020814) have been ongoing to evaluate the efficacy of FDG-PET in nivolumab therapy for NSCLC (Table 2). In the other fields, there are also some ongoing trials

\begin{tabular}{|c|c|c|c|c|c|c|c|}
\hline Identifier & Official title & Condition & Phase & $\begin{array}{l}\text { Estimated } \\
\text { enrollment }\end{array}$ & primary endpoint & Status & Region \\
\hline UMIN000020707 & $\begin{array}{l}\text { FDG-PET/MRI imaging for the evaluation } \\
\text { of early response to nivolumab in } \\
\text { patients with previously treated non- } \\
\text { small cell lung cancer }\end{array}$ & $\begin{array}{l}\text { Previously treated } \\
\text { non-small cell } \\
\text { lung cancer }\end{array}$ & N.A. & 25 & $\begin{array}{l}\text { Relationship between } \\
\text { serial FDG-PET/MRI } \\
\text { findings and progression } \\
\text { free survival and tumor } \\
\text { response }\end{array}$ & Recruit & Japan \\
\hline UMIN000020814 & $\begin{array}{l}\text { Usefulness of FDG-PET/CT to predict the } \\
\text { response after nivolumab in patients } \\
\text { with previously treated advanced non- } \\
\text { small cell lung cancer }\end{array}$ & $\begin{array}{l}\text { Previously treated } \\
\text { advanced non- } \\
\text { small cell lung } \\
\text { cancer }\end{array}$ & N.A. & 30 & $\begin{array}{l}\text { Changing of SUVmax, } \\
\text { MTV and TLG, and the } \\
\text { efficacy of nivolumab }\end{array}$ & Recruit & Japan \\
\hline NCT02716077 & $\begin{array}{l}\text { Early FDG-PET/CT imaging as a measure } \\
\text { of response in patients with melanoma } \\
\text { on pembrolizumab }\end{array}$ & $\begin{array}{l}\text { Clinical stage III } \\
\text { nodal or intransit } \\
\text { disease or } \\
\text { resectable stage } \\
\text { IV melanoma }\end{array}$ & 1 & 20 & Disease-free survival & Recruit & $\begin{array}{l}\text { United } \\
\text { States }\end{array}$ \\
\hline NCT02791594 & $\begin{array}{l}\text { Imaging the flare response with FDG- } \\
\text { PET/CT in patients with advanced } \\
\text { metastatic melanoma on pembrolizumab }\end{array}$ & $\begin{array}{l}\text { Matastatic } \\
\text { melanoma }\end{array}$ & N.A. & 30 & $\begin{array}{l}\text { Number of complete } \\
\text { response or partial } \\
\text { response or } \\
\text { nonresponders to CT }\end{array}$ & Recruit & $\begin{array}{l}\text { United } \\
\text { States }\end{array}$ \\
\hline
\end{tabular}

FDG-PET/MRI: 18F-fluorodeoxyglucose-positron emission tomography/magnetic resonance imaging, CT: Computed tomography, MTV: Metabolic tumor volume, TLG: Total lesion glycolysis

Table 2: Ongoing clinical trials using PET imaging for evaluating checkpoint-based immunotherapy 
for the evaluation of FDG-PET imaging, including a trial for the evaluation of early FDG-PET/CT imaging in predicting response to treatment with pembrolizumab in patients with advanced melanoma (NCT02716077) and another trial for measuring early response to pembrolizumab in patients with advanced metastatic melanoma (NCT02791594). We expect these prospective studies would resolve whether or not a PET/CT scan after one treatment is an accurate predictor of response.

\section{Conclusions and future directions}

To resolve the lack of imaging tools to assess the dynamic PD-L1 expression, non-invasive immunoPET imaging of human PD-L1 expression was designed using a small high-affinity engineered protein scaffold in a pre-clinical model ${ }^{64}$. Some small-engineered protein radiotracers enabled much earlier detection of human PD-L1 expression than previously reported radiolabeled antibodies, and small high-affinity engineered proteins will eventually be used to predict and monitor responders to clinical immune checkpoint inhibitors ${ }^{64}$.

There are also some reports of pre-clinical cancer immunotherapy studies such as photoimmunotherapy based on a monoclonal antibody conjugated to a highly specific photosensitizer that uses a near-infrared phthalocyanine dye $\mathrm{e}^{65,66}$, and combinatorial PD-1 blockade therapy with mitochondrial activation chemicals ${ }^{67}$. The former photoimmunotherapy induced immediate cytotoxic effects, which were detected as decreased glucose uptake using FDG-PET even before changes in tumor size became evident.

The latter combination therapy may pave a way to developing new combination therapies in the future; however, the combination therapy might also affect the image evaluation and immune-related adverse events in clinical practice.

Other immune checkpoint inhibitors may be clinically indicated in the future, such as PD-L1 antibody ${ }^{68}$ and CTLA4 antibody ${ }^{69}$ in NSCLC treatment and the combination therapies with immune checkpoint inhibitors ${ }^{70}$, EGFR-TKI, ALK TKI, anti-VEGF antibody, and anti- VEGFR antibody in combination with cytotoxic anti-cancer agents. The relationship between these combinations and the local metabolic milieu of each lesion is unclear, and these combination therapies might affect microenvironment and glucose metabolism, possibly with their own signature pattern on PET. More research in this area is needed.

\section{References}

1. Surveillance, epidemiology, and end results (SEER) cancer statistics review, 1975-2010. http://seer.cancer.gov/csr/1975_2010. Accessed 14 June, 2013.

2. Scagliotti GV, Parikh P, von Pawel J, et al. Phase III study comparing cisplatin plus gemcitabine with cisplatin plus pemetrexed in chemotherapy-naïve patients with advanced-stage non small cell lung cancer. J Clin Oncol. 2008; 26: 3543-3551.

3. Mok TS, Wu Y, Thongprasert S, et al. Gefitinib or carboplatin paclitaxel in pulmonary adenocarcinoma. N Engl J Med. 2009; 361: 947-957.

4. Ciuleanu T, Brodowicz T, Zielinski C, et al. Maintenance pemetrexed plus best supportive care versus placebo plus best supportive care for non-small cell lung cancer a randomized double blind phase 3 study. Lancet. 2009; 374: 1432-1440.

5. Fossella FV, DeVore R, Kerr RN, et al. Randomized phase III trial of docetaxel versus vinorelbine or ifosfamide in patients with advanced non-small cell lung cancer previously treated with platinumcontaining chemotherapy regimens. J Clin Oncol. 2000; 18: 23542362.

6. Shepherd FA, Dancey J, Pamlau R, et al. Prospective randomized trial of docetaxel versus best supportive care in patients with non-small cell lung cancer previously treated with platinum-based chemotherapy. J Clin Oncol. 2000; 18: 2095-2103.

7. Shepherd FA, Rodrigues Pereira J, Ciuleanu T, et al. Erlotinib in previously treated non-small cell lung cancer. N Engl J Med. 2005; 353: 123-132.

8. Hanna N, Shepherd FA, Fossella FV, et al. Randomized phase III trial of pemetrexed versus docetaxel in patients with non-small cell lung cancer previously treated with chemotherapy. J Clin Oncol. 2004; 22: 1589-1597.

9. Shaw AT, Kim DW, Nakagawa K, et al. Crizotinib versus chemotherapy in advanced ALK-positive lung cancer. N Engl J Med. 2013; 368: 23852394.

10. Ishida Y, Agata Y, Shibahara K, et al. Induced expression of PD-1 a novel member of the immunoglobulin gene superfamily upon programmed cell death. EMBO J. 1992; 11: 3887-3895.

11. Nishimura H, Minato N, Nakano T, et al. Immuno-logical studies on PD-1 deficient mice implication of PD-1 as a negative regulator for $\mathrm{B}$ cell responses. Int Immunol. 1998; 10: 1563-1572.

12. Iwai Y, Ishida M, Tanaka Y, et al. Involvement of PD-L1 on tumor cells in the escape from host immune system and tumor immunotherapy by PD-L1 blockade. PNAS. 2002; 22: 12293-12297.

13. Brahmer J, Reckamp KL, Baas P, et al. Nivolumab versus Docetaxel in Advanced Squamous-Cell Non-Small-Cell Lung Cancer. N Engl J Med. 2015; 373: 123-135.

14. Borghaei H, Paz-Ares L, Horn L, et al. Nivolumab versus docetaxel in advanced nonsquamous non-small-cell lung cancer. N Engl J Med. 2015; 373: 1627-1639.

15. Reck M, Rodriguez-Abreu D, Robinson AG, et al. Pembrolizumab versus chemotherapy for PD-L1-positive non-small-cell lung cancer. N Engl J Med. 2016; 375: 1823-1833.

16. Schima W, Kulinna C, Langenberger $\mathrm{H}$, et al. Liver metastases of colorectal cancer US CT or MR. Cancer Imaging. 2005; 5: S149-156.

17. Bipat S, van Leeuwen MS, Comans EF, et al. Colorectal liver metastases: CT, MR imaging, and PET for diagnosis meta-analysis. Radiology. 2005; 237: 123-131.

18. Quaia E, D’Onofrio M, Palumbo A, et al. Comparison of contrastenhanced ultrasonography versus baseline ultrasound and contrastenhanced computed tomography in metastatic disease of the liver: diagnostic performance and confidence. Eur Radiol. 2006; 16: 15991609.

19. Higuchi M, Suzuki H, Gotoh M. Role of PET/computed tomography in radiofrequency ablation for malignant pulmonary tumors. PET Clin. 2016; 11: 47-55.

20. Higuchi M, Honjo H, Shigihara T, etal. A phase II study of radiofrequency 
ablation therapy for thoracic malignancies with evaluation by FDGPET. J Cancer Re Clin Oncol. 2014; 140: 1957-1963.

21. Alafate A, Shinya T, Okumura $\mathrm{Y}$, et al. The maximum standardized uptake value is more reliable than size measurement in early follow-up to evaluate potential pulmonary malignancies following radiofrequency ablation. Acta Med Okayama. 2013; 67: 105-112.

22. Higaki F, Okumura $\mathrm{Y}$, Sato $\mathrm{S}$, et al. Preliminary retrospective investigation of FDG-PET/CT timing in follow-up of ablated lung tumor. Ann Nucl Med. 2008; 22: 157-163.

23. Weber WA. Use of PET for monitoring cancer therapy and for predicting outcome. J Nucl Med. 2005; 46: 983-995.

24. Lynch TJ, Bondarenko I, Luft A, et al. Ipilimumab in combination with paclitaxel and carboplatin as first-line treatment in stage IIIB/IV non-small-cell lung cancer results from randomized double-blinded multicenter phase II study. J Clin Oncol. 2012; 30: 2046-2054.

25. Gajewski TF, Schreiber H, Fu YX. Innate and adaptive immune cells in the tumor microenvironment. Nat Immunol. 2013; 14: 1014-1022.

26. Hanahan D, Coussens LM. Accessories to the crime functions of cells recruited to the tumor microenvironment. Cancer Cell. 2012; 21: 309322.

27. Vesery MD, Kershaw MH, Schreiber RD, et al. Natural innate and adaptive immunity to cancer. Annu Rev Immunol. 2011; 29: 235-271.

28. Galon J, Angell HK, Bedognetti D, et al. The continuum of cancer immunosurveillance prognostic predictive and mechanistic signatures. Immunity. 2013; 39: 11-26.

29. Galon J, Costes A, Sanchez-Cabo F, et al. Type, density, and location of immune cells within human colorectal tumors predict clinical outcome. Science. 2006; 313: 1960-1964.

30. Restifo NP. A "big data" view of the tumor "immunome". Immunity. 2013; 39: 631-632.

31. Whisteside TL. Immune responses to cancer are they potential biomarker of prognosis. Front Oncol. 2013; 3: 3-107.

32. Remark R, Becker C, Gomez JE, et al. The non-small cell lung cancer immune contexture. A major determinant of tumor characteristics and patient outcome. Am J Respir Crit Care Med. 2015; 191: 377-390.

33. Passon-McDermott EM, O'Neill LAJ. The Warburg effect then and now from cancer to inflammatory diseases. BioEssays. 2013; 35: 965-973.

34. Appelberg R, Moreira D, Barriera-Silva P, et al. The Warburg effect in mycobacterial granulomas is dependent on the recruitment and activation of macrophages by interferon- $\gamma$. Immunology. 2015; 145 : 498-507.

35. Chang CH, Qiu J, O'Sullivan D, et al. Metabolic competition in the tumor microenvironment is a driver of cancer progression. Cell. 2015; 162: 1229-1241.

36. Lopci E, Toschi L, Grizzi F, et al. Correlation of metabolic information on FDG-PET with tissue expression of immune markers in patients with non-small cell lung cancer (NSCLC) who are candidates for upfront surgery. Eur J Nucl Med Mol Imaging. 2016; 43: 1954-1961.

37. Yi CA, Lee KS, Kim BT, et al. Tissue characterization of solitary pulmonary nodule comparative study between helical dynamic CT and integrated PET/CT. J Nucl Med. 2006; 47: 443-450.

38. Rohren EM, Turkington TG, Coleman RE. Clinical application of PET in oncology. Radiology. 2004; 231: 305-332.

39. Keider Z, Haim N, Guralnik L, et al. PET/CT using 18F-FDG in suspected lung cancer recurrence diagnostic value and impact on patient management. J Nucl Med. 2004; 45: 1640-1646.

40. Gupta NC, Graeber GM, Rogers JS $2^{\text {nd }}$, et al. Comparative efficacy of positron emission tomography with FDG and computed tomographic scanning in preoperative staging of non-small cell lung cancer. Ann Surg. 1999; 220: 286-291.
41. Marom EM, Sarvis S, Herndon JE $2^{\text {nd }}$, et al. T1 lung cancers sensitivity of diagnosis with fluorodeoxyglucose PET. Radiology. 2001; 223: 453459.

42. Vansteenkiste JF, Stroobants SG. The role of positron emission tomography with $18 \mathrm{~F}$-fluoro-2-deoxy-D-glucose in respiratory oncology. Eur Respire J. 2001; 17: 802-820.

43. Gould MK, Maclean CC, Kuschner WG, et al. Accuracy of positron emission tomography for diagnosis of pulmonary nodules and mass lesions a meta-analysis. JAMA. 2001; 285: 914-924.

44. Fischer BM, Mortensen J, Hojgaard L. Positron emission tomography in the diagnosis and staging of lung cancer a systematic quantitative review. Lancet Oncol. 2001; 20: 659-666.

45. Higuchi M, Hasegawa T, Osugi J, et al. Prognostic impact of FDG-PET in surgically treated pathological stage I lung adenocarcinoma. Ann Thorac Cardiovasc Surg. 2014; 20: 185-191.

46. Shiono S, Abiko M, Okazaki T, et al. Positron emission tomography for predicting recurrence in stage I lung adenocarcinoma standardized uptake value corrected by mean liver standardized uptake value. Eur J Cardiothorac Surg. 2011; 40: 1165-1169.

47. Abe Y, Matsuzawa T, Fujiwara T, et al. Clinical assessment of therapeutic effects on cancer using 18F-2-fluoro-2-deoxy-D-glucose and positron emission tomography preliminary study of lung cancer. Int J Radiat Oncol Biol Phys. 1990; 19: 1005-1010.

48. Akhurst T, Downey RJ, Ginsberg MS, et al. An initial experience with FDG-PET in the imaging of residual disease after induction therapy for lung cancer. Ann Thorac Surg. 2001; 73: 259-264.

49. Frank A, Lefkowitz D, Jaeger S, et al. Decision logic for retreatment of asymptomatic lung cancer recurrence based on positron emission tomography findings. Int J Radiat Oncol Biol Phys. 1995; 32: 14951512 .

50. Herbert ME, Lowe VJ, Hoffman JM, et al. Positron emission tomography in the pretreatment evaluation and follow-up of non-small cell lung cancer patients treated with radiotherapy: preliminary findings. Am J Clin Oncol. 1996; 19: 416-421.

51. Patz EF Jr, Connolly J, Hendon J. Prognostic value of thoracic FDG PET imaging after treatment for non-small cell lung cancer. AJR Am J Roentgenol. 2000; 174: 769-777.

52. Zhang L, Wang Y, Lei J, et al. Dual time point 18FDG-PET/CT versus single time point 18FDG-PET/CT for the differential diagnosis of pulmonary nodules a meta-analysis. Acta Radiologica. 2013; 54: 770 777.

53. Nakajima R, Matsuo $\mathrm{Y}$, Kondo T, et al. Prognostic value of metabolic tumor volume and total lesion glycolysis on preoperative 18F-FDG PET/CT in patients with renal cell carcinoma. Clin Nucl Med. 2017 Jan 27. doi: 10. 1097/RLU. 0000000000001552. [Epub ahead of print].

54. Bazan JG, Duan F, Snyder BS, et al et al. Metabolic tumor volume predicts overall survival and local control in patients with stage III non-small cell lung cancer treated in ACRIN 6668/RTOG 0235. Eur J Nucl Med Mol Imaging. 2017; 44: 17-24.

55. Eisenhauer EA, Therasse P, Bogaerts J, et al. New response evaluation criteria in solid tumours revised RECIST guideline (version 1.1). Eur J Cancer. 2009; 45: 228-247.

56. Wolchok JD, Hoos A, O'Day S, et al. Guideline for the evaluation of immune therapy activity in solid tumors immune related response criteria. Clin Cancer Res. 2009; 15: 7412-7420.

57. Young H, Baum R, Cremerius U, et al. Measurement of clinical and subclinical tumour response using [18F]-fluorodeoxyglucose and positron emission tomography: review and 1999 EORTC recommendations. European Organization for Research and Treatment of Cancer (EORTC) PET Study group. Eur J Cancer. 1999; 35: $1773-1782$ 
58. Wahl RL, Jacene H, Kasamon Y, et al. From RECIST to PERCIST: evolving considerations for PET response criteria in solid tumors. J Nucl Med. 2009; 50 Suppl 1: 122S-50S.

59. Ziai D, Wagner T, El Badaoui A, et al. Therapy response evaluation with FDG-PET/CT in small cell lung cancer a prognostic and comparison study of the PERCIST and EORTC criteria. Cancer Imaging. 2013; 13 73-80.

60. Skougaard K, Nielsen D, Jensen BV, et al. Comparison of EORTC criteria and PERCIST for PET/CT response evaluation of patients with metastatic colorectal cancer treated with irinotecan and cetuximab. J Nucl Med. 2013; 54: 1026-1031.

61. Alagoz E, Ince $\mathrm{S}$, Okuyucu $\mathrm{K}$, et al. Complete remission on 18-fluorodeoxyglucose positron emission tomography/computed tomography after nivolumab treatment in a patient with indolent Hodgkin lymphoma. Transl Cancer Res. 2016; 5: 320-323.

62. Higuchi M, Owada Y, Inoue T, et al. FDG-PET in the evaluation of response to nivolumab in recurrent non-small- cell lung cancer. World J Surg Oncol. 2016; 14(1): 238. doi; 10.1186/s12957-016-0998-y.

63. Kong BY, Menzies AM, Saunders CAB, et al. Residual FDG-PET metabolic activity in metastatic melanoma patients with prolonged response to anti-PD-1 therapy. Pigment Cell Melanoma Res. 2016; 29: 572-577.

64. Mayer AT, Natarajan A, Gordon SR, et al. Practical immunoPET radiotracer design considerations for human immune checkpoint imaging. J Nucl Med. 2016 Dec 15. pii; jnumed. 116. 177659. [Epub ahead of print].
65. Sano K, Mitsunaga M, Nakajima T, et al. Acute cytotoxic effects of photoimmunotherapy assessed by 18F-FDG PET. J Nucl Med. 2013; 54: 770-775.

66. Nagaya T, Nakamura Y, Sato K, etal. Near infrared photoimmunotherapy with avelumab, an anti-programmed death-ligand 1 (PD-L1) antibody. Oncotarget. 2016 doi: 10. 18632/oncotarget. 12410. [Epub ahead of print].

67. Chamoto K, Chowdhury PS, Kumar A, et al. Mitochondrial activation chemicals synergize with surface receptor PD-1 blockade for T celldependent antitumor activity. Proc Natl Acad Sci. USA 2017; 114(5): E761-E770. doi: 10. 1073/pnas. 1620433114. Epub 2017 Jan 17.

68. Rittmeyer A, Barlesi F, Waterkamp D, et al. Atezolizumab versus docetaxel in patients with previously treated non-small-cell lung cancer (OAK) a phase 3 open-label multicenter randomized controlled trial. Lancet. 2017; 389: 255-265.

69. Calabro L, Morra A, Fonsatti E, et al. Efficacy and safety of an intensified schedule of tremelimumab for chemotherapy resistant malignant mesothelioma an open-label single-arm phase 2 study. Lancet. 2015; 3: 301-309.

70. Antonia S, Goldberg SB, Balmanoukian A, et al. Safety and antitumour activity of durvalumab plus tremelimumab in nonsmall-cell lung cancer a multicenter phase 1b study. Lancet. 2016; 17: 299-308. 